\title{
RECURSOS HUMANOS E MEIO AMBIENTE
}

MIRANDA MARTINELLI MAGNOLI*

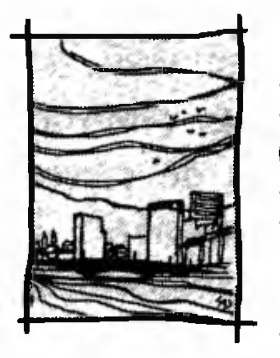

Este documento é uma contribuição para a temática de FORMAÇÃO de RECURSOS HUMANOS em relação ao MEIO AMBIENTE. É constituído de dois aspectos:

Antecedentes Gerais:

dá-se um panorama extremamente suscinto da questão ambiental enquanto problema internacional: por este panorama fica exposta a visão global que se adota.

\section{Abordagem Específica:}

indicam-se temáticas consideradas prioritárias na formação de recursos humanos: complementa-se em cada caso com aspectos fundamentais de abordagem; enquanto método sugere-se o projetual, aplicado no recorte da escala de atuação porém inserido, enquanto análise, nos vários níveis escalares de influência. Há uma sugestão de níveis escalares com exemplo de especificidades no tratamento de cada nível.

Consideramos oportuno o debate com os colegas e inadequada a apresentação de proposta fechada de curso.

\section{ANTECEDENTES GERAIS}

Já se passaram quinze anos do seminário prévio de Founex, na Suíça, em junho de 1971, em que se abordou a relação entre desenvolvimento e meio ambiente. É desse seminário a temática de "metas sociais" com a idéia de também medir o progresso nacional em termos de indicadores ambientais, criando conceitos ambientais mínimos. Este seminário prévio elaborou os princípios em que se basearia a comentada e polêmica $1^{\text {a }}$ Conferência Internacional sobre Ambiente Humano, promovida pelas Nações Unidas e realizada em Estocolmo em 1972. As transformações que se deram daquela época para cá são intensas e fundamentais. Na relação desenvolvimento e meio ambiente, surgindo como um processo praticamente indissolúvel, constituindo dois aspectos diferentes de um 
mesmo conceito. O conceito de desenvolvimento se apóia sobre uma realidade social, conformada pelo mundo das atividades humanas, pelas ações dos homens que se influem reciprocamente dentro da sociedade e portanto pela realidade física constituída pelo suporte ecológico, ou pelo entorno onde o homem desenvolve as ditas atividades e sobre cuja realidade física a ação de desenvolvimento toma constituição, toma corpo.

O lema que se pretendeu converter em símbolo na reunião de Estocolmo foi "UMA SÓ TERRA": ainda embasado na divulgação dos "limites de crescimento" com as teorias ricardianas e malthusianas, o estado estacionário de Stuart Will e posteriormente com a teoria keynesiana advogando soluções de curto prazo.

As abordagens limitadas a um mundo escassamente povoado para poder compor o crescimento exponencial da população com o crescimento linear da produção de alimentos haveriam de levar a outras reflexões sobre o futuro da humanidade, o crescimento econômico e o meio ambiente. Um dos primeiros elementos a mencionar do presente histórico é o caráter mundial dos estudos de alternativas para o futuro. Entre estas alternativas as mais discutidas foram: a de Pestow - capitais mais expansivos, a de Tnbergem, fortemente ecologista, a da escola francesa e a elaborada pelo MIT para o Clube de Roma: esta foi seguida por um trabalho de 1976 intitulado "A humanidade na encruzilhada" em que a visão problemas é aquela do ponto de vista dos países ricos (mundo desenvolvido) e seu destinatário principal é o homem que vive nesse quadro: não são também protagonistas as populações dos países pobres. Um modelo altamente complicado e sofisticado foi apresentado na Conferência das Nações Unidas sobre a Cooperação Técnica entre os Países em vias de Desenvolvimento. realizada em Buenos Aires em 1978. Em contraposição aos modelos que foram conhecidos como "dos ricos" começaram a se desenvolver estudos conhecidos como "modelos dos pobres": os países periféricos esboçam suas próprias teorias de crescimento em que é diferente o valor dado às variáveis postas em jogo; 0 problema não se enfoca no esgotamento dos recursos naturais, mas na falta de apoio financeiro, de mercado e de tecnologias em que os países subdesenvolvidos se encontram em relação aos desenvolvidos.

Esse tempo passado. desde os inícios de 70, mostrou que atribuir os problemas às múltiplas interações dos componentes físicos e biológicos do ambiente correspondia a uma análise. no mínimo, superficial. Ao conceito de meio ambiente seria necessário e fundamental colocar o homem social. Isto foi caracterizando os problemas ambientais de forma mais nítida. mais definida e mais objetiva. 
Também foi possível identificar dois níveis claramente distintos para as soluções propostas:

o nível das partes (merístico) que compreende ações isoladas, para problemas específicos e pontuais e que serviria como paliativo:

o nível da globalidade. do todo (holístico), onde se procuram soluçōes globais à problemática também global do meio ambiente.

Ficou claro, apesar de não devidamente difundido, que o conhecimento do meio ambiente requer analisar as vinculações entre as estruturas sociais e as estruturas naturais; o meio ambiente é visto como o resultado das interações entre os sistemas sócioeconômicos-culturais e os sistemas ecológicos; essas interaçōes provocam efeitos sobre as atividades humanas e os seres vivos e têm como variáveis:

qualidade (estabilidade e renovação) e quantidade (atual e potencial) dos recursos:

- a estrutura de relações estabelecidas entre os homens, em relação à produção em escalas nacional e internacional:

- o grau de desenvolvimento e a modalidade de tecnologias produtivas utilizadas.

A interação dinâmica entre essas variáveis dá em cada situação histórica concreta:

um certo modelo de utilização de recursos (vinculado a um tipo de racionalidade política e econômica):

um certo modelo de utilização do espaço nacional ou regional, urbano ou rural, como expressão física das relações produtivas.

Fica assim o meio ambiente como um sistema globalizador dos sistemas sócioeconômicos-culturais e dos sistemas ecológicos. O meio ambiente fica concebido como um nível superior de integração. Assim concebido pode-se perceber que a manifestação dos problemas ambientais de formas radicalmente distintas entre os países ricos e os países subdesenvolvidos são devidas às diferenças nas condições sociais existentes, já que as leis ecológicas são as mesmas em todo mundo. 
As estratégias de desenvolvimento passam a incluir a necessidade de cooperação entre setores sociais e entre regiões; de equilíbrio e reciprocidade entre os homens e entre a sociedade e a natureza; de disponibilidade, abertura para mudanças reais e estruturais, com alternativas para novos comportamentos em relação às instituições, aos meios de produção, à distribuição da riqueza; de complementariedade, aceitando a contigüidade da diversidade, da simplicidade, da estabilidade e da dinâmica, da variabilidade e a planificação para o previsível e também para o imprevisto. Dentro desses exemplos de estratégias políticas, cientes de que é falso o pressuposto de que o desenvolvimento tem custos ambientais altos, alguns problemas do meio ambiente tidos como críticos podem ser apontados: a mortalidade infantil, a fome, a urbanização descapitalizada, o problema habitacional urbano; a localização espacial das indústrias; a estrutura agrária, a realidade sócioeconômica do campo e a exploração dos recursos renováveis com a desterritorialização do homem.

Incorporada à idéia da característica humana de fazer o seu projeto, é também percebido que o projeto do homem social se faz sobre o suporte em que o homem vive o ambiente, em um projeto contínuo de momentos reflexivos, interpretativos e momentos construtivos - de transformação; estes momentos são simultâneos, sem solução de continuidade, permitindo ao homem reformular seu projeto precedente, ajustando-o a suas necessidades mais recentes e mais urgentes. Esses são processos do projeto da sociedade humana que se produzem através da formação. O que se pretende afirmar é que o ambiente humano não é um estado ou um objeto e da atuação humana enquanto enfrentado como tal: a cada momento a qualidade depende da maneira pela qual o homem está incluído no processo. São agentes desse processo: as populações, em suas organizações políticas, sociais, econômicas e culturais; o Estado e os profissionais.

\section{ABORDAGEM ESPECÍFICA}

A Faculdade de Arquitetura e Urbanismo da Universidade de São Paulo dá andamento, na área de Planejamento Ambiental e da Paisagem, no Departamento de Projeto, à introdução da dimensão ambiental. É restrita a poucas disciplinas (obrigatórias e optativas) no nível de graduação e a 7 disciplinas de pós-graduação apoiadas em pesquisas em andamento (em número de 20).

Indispensável se faz a destinação de maiores facilidades para a organização e elaboração de pesquisas e cursos, com maior número de docentes, pesquisadores e auxiliares de pesquisa. Os avanços dos estudos já permitem se possa criar uma linha dentro da formação de arquitetos, nos níveis de graduação e pós. Seria 
adequado conseguir-se a ampliação de espaços disciplinares de modo a obter formação específica no nível de graduação integrada a setores de outros cursos que a USP já dispõe. Em nível de pós-graduação, sentido lato, se tem um préprojeto de curso para ser desenvolvido em módulos que poderiam ser completados no período de um ano. Essa experiência seria fundamental para aperfeiçoamento das linhas temáticas que se tem em mente e para propiciar as oportunidades de melhor definição das interdisciplinariedades. Apresentam-se a seguir alguns aspectos que embasam essa abordagem.

Várias foram as aproximações estudadas para a problemática ambiental, a que mais atende aos conteúdos é aquela que vê o ambiente como cultura.

O espaço foi considerado como o lugar em que a sociedade pode com ele e por meio dele desenvolver-se e tornar-se histórica, coletiva, humana. Amplas são as faixas de contato com o conceito de ambiente na medida em que a sociedade vai imprimindo suas "marcas" no espaço, criando novas paisagens.

Acepção e Conceitos de Ambiente, Paisagem e Espaço é temática básica de ensino e pesquisa

A cultura ao ser causa e efeito da relação entre os homens com o suporte ecológico é, conseqüentemente, ativa. Esta é a forma pela qual têm sido elaboradas as "leituras" do ambiente, levando a uma interpretação do ambiente como a sede ativa da sociedade. É conceitualmente mais abrangente que a paisagem na abordagem do arquiteto. Por outro lado a interpretação cultural do ambiente vem de encontro aos avanços conceituais do ponto de vista ecológico: a ecologia geral tem conferido ao homem somente o caráter de homem biológico; é na ecologia cultural, mais até do que na ecologia humana que se compreende seu caráter histórico, a capacidade de mudanças, a capacidade de tomada de decisões humanas racionais e éticas: há portanto uma mudança de concepção filosófica ética embasada na visão do ambiente.

\section{Meio Ambiente Humano é temática básica de ensino e pesquisa}

Ao assumir o ambiente como cultura decorre que, analiticamente, compreendêlo significa conhecer a cultura de um povo, de um grupo (aquela sociedade), suas riquezas, seus problemas e conflitos. $\mathrm{E}$, ao nível de proposição (passado, presente, futuro) qualitativa, a análise nos leva a objetivar a qualidade ambiental como aumento da qualidade de vida desse povo. A qualidade de vida deixa de ser uma condição genérica para se consubstanciar de maneira concreta e espe- 
cífica de cada indivíduo e grupo, de cada tempo e lugar. Isso implica em que um país (território) se torne paisagem (lugar de vida dos habitantes do país, com sua história, suas raízes, sua cultura) deixando de ser simplesmente um espaço a espera de uso predatório.

Aspectos de Antropização do País é temática que exige pesquisa para posterior rebatimento no ensino

Ao procurar compreender a questão ambiental faz-se necessário elucidar as tendências ambientais no decorrer da história. Começamos pelo presente, procurando no passado os contextos dos conflitos de hoje, para na compreensão das transformações e da difusão de inovações poder vir a estudar alternativas para o futuro. A juventude como nação e a dimensão territorial revelam de pronto alguns marcos de estudo do processo de antropização do país e chamam atenção para a ampliação de ocupação e uso utilitário e imediatista do território ao invés de humanização do mesmo.

Nos estudos antropológicos referentes ao período pré-colonial poucos são os casos em que se assinalam exemplos ambientais de referência ao comportamento e à personalidade. Além dos aspectos filológicos poucos são os traços que nos ficaram: em geral se resumem à asseveração da grande adaptação em relação ao suporte ecológico e grau extremamente reduzido de tomada de decisões que impliquem em transformações do meio.

Para o país pré-industrial (colonial e pós-colonial século XVI a XIX) se identificam momentos, espaços e paisagens onde houve uma real antropização. Em uma tentativa muito preliminar se indicam os seguintes tipos:

a) assentamentos urbanos: o esquema português tem um modelo de assentamento com características de situação, criação de um lugar, inter-relação com o exterior muito peculiar. É importante observar que difere totalmente daquele que deu origem às cidades de fundação hispânica (Lei das Índias, código de Felipe).

b) assentamentos em áreas rurais: relacionados às sedes de fazendas dos ciclos do açúcar e posteriormente do café e aos assentamentos das missões jesuíticas.

O Ambiente na História, no Brasil é temática de pesquisa para rebatimento no ensino

O país com crescimento econômico baseado na economia de mercado, na industrialização e na terciarização em situação periférica, dependente de modelos de 
consumo exteriores ao país: macroconcentração urbana, periféricas com péssimas condições de vida, migração interna intensa, extração descontrolada de recursos, extinção de espécies da fauna, devastação de reservas naturais da flora, degradaçāo e desaparecimento de paisagens do patrimônio cultural sāo características do período.

A problemática ambiental durante as últimas décadas não foi enfrentada explicitamente; as exceções são isoladas e raras com preocupaçōes de caráter estético ou preservacionista. As duas últimas décadas foram destinadas ao crescimento sem um desenvolvimento integral: caracterizam-se as metrópoles e as megametrópoles, construíram-se usinas nucleares, represas, complexos industriais, habitações coletivas, transformações urbanas em volume de transformação acelerada, em todos os setores e em todas as escalas; nessas transformações. pela conjuntura, o impacto de efeitos secundários multiplicadores ficou para trás nas tomadas de decisões:

É dos últimos anos o aparecimento de preocupações acentuadamente críticas pela maneira em que vem sendo usado o território, quer em seus grandes espaços rurais, quer nas cidades.

O Ambiente e os Planos Nacionais de Desenvolvimento das duas últimas décadas é temática indispensável em seus enfoques globais e nos enfoques particularizados: o ambiente e os pólos petroquímicos/ e a produção açucareira e algodoeira e a produção de carvão mineral/ e o saneamento básico/ e a estrutura agrária contemporânea/ e a energia

Os principais problemas ambientais decorrentes das implantações dos "grandes projetos" deverão ser estudados em relação à estruturação ambiental nacional relativa à antropização. São temáticas de ensino e pesquisa.

Requisitos indispensáveis para enfrentar as questões:

participação da população, enquanto usuária; problemática complexa, de processo lento já que se presta facilmente a mistificações pela instrumentação ideológica dos usuários ou pela simplória transferência ao usuário do papel de conferir soluções técnicas em atribuições que não lhe cabem. É difícil encontrar forma de participação do usuário de tal forma que ao conferir ao coletivo o processo decisório se responda às tendências culturais reais, levando em conta a riqueza das diversidades; 
- racionalização das atividades na organização do uso do solo do território; implica em substituir e/ou completar o tradicional planejamento físico por um planejamento integral dos requisitos sócioprodutivos em sua relação com as potencialidades do suporte ecológico e, mais especialmente com as reais necessidades de bem-estar da população e a disponibilidade de aplicação do conhecimento tecnológico;

elaboração de políticas setoriais amplas para a produção agrícola-pastoril, industrial e de infra-estrutura essencial (energia, irrigação, saneamento) que se proponham avaliar o uso de recursos não tradicionais, em função dos requisitos de bem-estar da população e das oportunidades e limitações;

- conservação e preservação do patrimônio natural, histórico e da memória, é preocupação bastante recente e de estratégias de difícil definição e muito especialmente, de implantação; por mais contraditório que possa parecer, em um país com tantas necessidades e tanto por fazer, uma série de conjunturas fez com que a depredação e/ou degradação de ambientes se sucedesse sem maiores embargos: a própria discussão do peso histórico ou natural precisa ser revista já que eivada de conotações alienígenas e polêmicas; qualquer que seja porém o consenso que se faça uso, a situação a que se chegou acaba por exigir medidas urgentes e intensas para se contar com ecossistemas indispensáveis, recuperação de espécies, revalorização de ambientes significativos; uma série de interesses geopolíticos deverão ser enfrentados nas macrorrelações aliados a interesses de grupos internos;

compreensão e visão do contexto; o ambiente é visto como a sede dos elementos mais importantes e comuns a todos os fatos do meio humano: se materializa pela paisagem no espaço. A progressiva massificação do homem contemporâneo e a baixa identificação e pertinência do contexto urbano atual levam a que se distingam alguns aspectos como fundamentais para situar o habitat em seu entorno físico e social, de modo a definir uma porção de mundo, um "lugar", os "lugares urbanos". Dentre esses aspectos já é possível indicar:

a valorização do espaço público, lugares urbanos comuns a todos, espaço social por excelência;

a valorização das "formas pelo seu conteúdo"; ler o espaço enquanto sistema de signos, reconhecendo à matéria seu caráter significante pelos próprios usos, estes também imbuídos de seu significante.

- ao fazer uso de um ponto de vista ecológico, entendê-lo de forma ampla, abrangente, relativizando as interpretações das disciplinas tradicionais e cobrando a necessidade de visão integral; 
o movimento da paisagem, questão diretamente relacionada à adequação e adaptação; as formas têm sua gênese estreitamente vinculada a um contexto que é o que lhe confere conteúdo; as transformações (de papéis regionais e urbanos, de padrões de comportamento, de consumo, de uso do espaço) levam à inadequação de estruturas e funcionamentos dos ambientes: faz-se necessário enfrentar a questão incluindo desde a concepção às oportunidades de alteração, mudanças, adaptação, substituição nas formas de maneira rápida e/ou freqüente e sem intensos impactos.

Os requisitos indicados decorrem de uma observação de aspectos que se apresentam com maior freqüência nos últimos anos em que a questão ambiental começou a se difundir. Por mais desarticulados e fragmentados que se mostrem é possível notar que vem se criando uma situação que deverá levar ao enfrentamento da problemática ambiental. Parece importante adotar critérios para selecionar e analisar criticamente a produção de estudos, projetos, programas e obras que incidam diretamente no aumento da qualidade ambiental.

Abordagem de projeto analisada simultaneamente em todas as escalas para atuação em escala específica. Optamos inicialmente pelas seguintes:

- do espaço do território enquanto nação;

- do espaço regional:

- do espaço metropolitano:

do espaço urbano;

do espaço do "lugar"

Esses níveis escalares são considerados principais; para cada um dos níveis serão necessários estudos de abordagem específica; as características de qualidade ambiental que articulam o espaço na globalidade (da macro e da micropaisagem) faz-se necessário acrescer as características daquela fração, as oportunidades e limitações de cada entorno em cada escala.

Em todo nível dever-se-á poder extrapolar levando em conta um quadro metodológico abrangente, que cumpre alguns papéis fundamentais tais como: modificações do comportamento, do uso dos recursos. da cultura e adaptação ao clima. Percebe-se que na extrapolação referida, as modificações dos comportamentos se torna coletiva, sendo portanto social o seu significado: a modificação 
de uso dos recursos se refere à adoção de outras tecnologias e por ela a mudanças de escala técnica e de significado e metas políticas (e não somente à correta utilização de materiais e energia em um projeto arquitetônico); a adaptação ao clima se refere a processos ecossistêmicos naturais de grande magnitude (construção de reservatórios, irrigação de áreas áridas, avaliação de extensos espaços concentradamente urbanizados); a modificação na cultura, entendida como patrimônio significativo e simbólico, se realiza no contexto que lhe é próprio, o da sociedade e não aplicada a um objeto isolado. A cada programa ou projeto se procura dirigir para o cumprimento desses papéis, sem o que avaliamos que é de resposta setorial ou proto-ambiental. Por outro lado é próprio do ciclo de processo de projeto a inclusão de quatro momentos fundamentais:

Objetivos - definição das finalidades e metas da ação de projeto.

Conflitos - determinação de problemas ou desajustes que se opõem aos objetivos.

Síntese proposta de solução dos conflitos, hierarquização, estratégia de implantação, execução, implementação.

Avaliação retroação necessária para conhecer em que medida a síntese era adequada. se os objetivos propostos são atingidos, e o que há pra alterar e corrigir para seguir no processo ambiental desejado, levando em conta a dinâmica da paisagem.

Em cada um dos níveis escalares são necessários prioritariamente:

\section{Na escala do espaço do território}

Política nacional do meio ambiente - compreensão da situação do país face aos diferentes blocos de países: ricos e pobres / dos hemisférios Norte e Sul / do Leste e Oeste / dos países desenvolvidos e subdesenvolvidos e face à Estratégia Mundial de Conservação da Natureza (IUCN-UNEP-WWF); compreensão dos domínios naturais pelas estruturas fisiográficas básicas (geomorfologia, hidrografia, domínios morfoclimáticos); levantamento de fontes, compatibilização de dados e mapeamento da vegetação brasileira em vinte e uma tipologias: levantamento e mapeamento de antropização por meio de:

- obras pontuais de infra-estrutura, porém de impacto sobre o ambiente barragens, reservatórios e usinas para produção de energia. irrigação e abastecimento: compreensão do papel dessas obras no processo de desenvolvimento 
nacional, consequiências de caráter regional, situações locais (oportunidades e limitações) e questão de tratamento paisagístico.

obras pontuais industriais de impacto sobre o ambiente-pólos petroquímicos: foram também levantados dados sobre cada um dos pólos e as condições atuais de ambiente prejudicado.

concentração de indústrias pesadas com impacto sobre o ambiente.

urbanização (com levantamento e mapeamento dos núcleos urbanos em sete faixas de população, sendo a menor aquela entre 50.000 e 100.000 hab. aproximadamente 300 cidades).

- densidade demográfica por regiōes e movimentos migratórios na criação de novas fronteiras.

- inventário e mapeamento das áreas de preservação, existentes e em estudo, ordenada em diferentes tipologias - parques nacionais. estações ecológicas, reservas biológicas, reservas florestais, áreas de proteção ambientais e áreas protegidas.

inventário e análise de agroindústria açucareira-alcooleira e o impacto sobre o ambiente.

inventário e ordenação da legislação para proteção à natureza, de acordo com diferentes setores de atuação.

- estudos sobre programas de gerenciamento de estações ecológicas.

- elaboração de textos específicos sobre os aspectos estudados e de texto sobre a relação entre qualidade do ambiente, paisagem e contribuição do arquiteto.

\section{Na escala do espaço regional}

A interação do espaço regional no espaço do território ambiental.

determinação de tipologias do espaço regional em relação aos usos do solo (foram organizados 13 tipos com subtipos) de modo a poder analisar as predominâncias, polivalências e compatibilizações a partir dos critérios específicos de cada espaço-uso e das articulaçōes entre os vários espaços-uso.

abordagem compreensiva dos principais aspectos e problemas que se apresentam para a análise de um espaço regional, tendo em vista o planejamento paisagístico. 
os grandes espaços livres das periferias de urbanização; aborda a valorização das áreas rurais como zonas naturais "de equilíbrio"

- métodos de planejamento paisagístico e de avaliação das características físicas e humanas da paisagem.

\section{Na escala do espaço metropolitano}

A conurbação física e as políticas municipais sobre os espaços livres (sobre o caso da Região Metropolitana de São Paulo).

inventário e levantamento de dados sobre os grandes espaços livres em São Paulo.

- abordagem compreensiva dos espaços livres recreacionais metropolitanos.

- acessibilidade pelo transporte coletivo aos espaços livres recreacionais metropolitanos.

estudos para estratégias de previsão em relação a futuras regiões metropolitanas.

a infra-estrutura em corpos d'água e o ambiente metropolitano.

\section{Na escala do espaço urbano}

Aspectos ambientais e paisagísticos.

texto sobre os espaços livres urbanos: a questão de sua distribuição como a chave da interação escalar desde o cotidiano ao espaço da região urbana.

estudos sobre os espaços livres interiores à mancha urbana e a morfologia da urbanização.

estudos sobre as tipologias de espaços livres urbanos - parques urbanos.

os parques, a urbanização e o sistema de espaços livres.

- o projeto de parques e o contexto social: análise a partir da evolução dos parques americanos clássicos na história do paisagismo.

- ensaios para análise dos parques urbanos em face da questão recreação; as necessidades recreacionais e os fatores de desempenho.

Texto originalmente publicado no Paisagem e Ambiente - Ensaios II.

(*) Arquiteta paisagista, professora titular e doutora pela FAUUSP, pesquisadora e orientadora do Grupo de Disciplinas Paisagem e Ambiente do Departamento de Projeto FAUUSP. 